\title{
Correction to: The reliability and validity of the Japanese version of the daily record of severity of problems (J-DRSP) and development of a short-form version (J-DRSP (SF)) to assess symptoms of premenstrual syndrome among Japanese women
}

\author{
Yumie Ikeda ${ }^{1 *}$, Miho Egawa², Kazuya Okamoto ${ }^{3}$, Masaki Mandai ${ }^{2}$, Yoshimitsu Takahashi ${ }^{1}$ and Takeo Nakayama ${ }^{1}$ \\ Correction to: BioPsychoSocial Med 15, 6 (2021). \\ https://doi.org/10.1186/s13030-021-00208-z

\section{Supplementary Information} \\ The online version contains supplementary material available at https://doi. \\ org/10.1186/s13030-021-00231-0.
}

Following publication of the original article [1], the authors reported the additional information, which are marked in red in the attached Word file (Additional file 1).

(1) In the Methods section (Line 4 6, Page 9), the below sentences are added:

In order to confirm the criteria validity for J-DRSP (SF), we calculated Pearson's coefficients, with $p$ values, between the total score of the 8 items of J-DRSP (SF) and J-DRSP.

Two sided tests were done with a significance level of 0.001 .

(2) In the Results section (Line $15 \sim 16$, Page 11), the below sentence is added:

The result of correlation coefficient between JDRSP(SF) and J-DRSP was 0.97, with p value $<0.0001$.

The original article [1] has been corrected.
Additional file 1. Revised manuscript.

Author details

'Department of Health Informatics, Kyoto University School of Public Health, Konoecho Yoshida, Sakyo-ku, Kyoto City 606-8303, Japan. ${ }^{2}$ Department of Obstetrics and Gynecology, Kyoto University Hospital, 54 Kawaramachi Shogoin, Sakyo-ku, Kyoto City 606-8397, Japan. ${ }^{3}$ Department of Medical Informatics, Kyoto University Hospital, 54 Kawaramachi Shogoin, Sakyo-ku, Kyoto City 606-8397, Japan.

Published online: 31 December 2021

\section{Reference}

1. Ikeda Y, Egawa M, Okamoto K, Mandai M, Takahashi Y, Nakayama T. The reliability and validity of the Japanese version of the daily record of severity of problems (J-DRSP) and development of a short-form version (J-DRSP (SF)) to assess symptoms of premenstrual syndrome among Japanese women. BioPsychoSocial Med. 2021;15(1):6. https://doi.org/10.1186/s13030-021-002 08-z.

The original article can be found online at https://doi.org/10.1186/s13030021-00208-z.

* Correspondence: yumieikeda@kuhp.kyoto-u.ac.jp

'Department of Health Informatics, Kyoto University School of Public Health, Konoecho Yoshida, Sakyo-ku, Kyoto City 606-8303, Japan

Full list of author information is available at the end of the article

C C The Author(s). 2021 Open Access This article is licensed under a Creative Commons Attribution 4.0 International License, which permits use, sharing, adaptation, distribution and reproduction in any medium or format, as long as you give appropriate credit to the original author(s) and the source, provide a link to the Creative Commons licence, and indicate if changes were made. The images or other third party material in this article are included in the article's Creative Commons licence, unless indicated otherwise in a credit line to the material. If material is not included in the article's Creative Commons licence and your intended use is not permitted by statutory regulation or exceeds the permitted use, you will need to obtain permission directly from the copyright holder. To view a copy of this licence, visit http://creativecommons.org/licenses/by/4.0/ The Creative Commons Public Domain Dedication waiver (http://creativecommons.org/publicdomain/zero/1.0/) applies to the data made available in this article, unless otherwise stated in a credit line to the data. 